\title{
Cardiovascular disease and its association with body mass index: A study of rural women of Uttarakhand
}

\section{Janki Joshi and Nidhi Trivedi}

Received: 24.06.2019; Revised: 20.10.2019; Accepted: 04.11.2019

See end of the paper for authors' affiliations

\section{Janki Joshi}

Department of Home Science,

Surajmal Agarwal Private Kanya

Mahavidyala, Kichha

(Uttarakhand) India

Email : janki.30121@gmail.com
ABSTRACT : Cardiovascular diseases (CVD), in broad terms, comprise diseases of the heart, blood vessels and circulation. The most common cardiovascular diseases are hypertension, coronary heart diseases, cerebrovascular diseases, and peripheral vascular diseases. Cardiovascular disease causes million deaths among women annually. It is the largest and single cause of mortality among women, accounting for one-third of all deaths among women worldwide. Present study was conducted to assess to see the association between occurrence of CVD and the respondents Body Mass Index. For this Chi-square test was applied and the results were found to be significant at $\mathrm{p}<0.05$, indicating that occurrence of CVD among respondent depends on the respondents BMI. Respondents with higher BMI level had greater chances of heart disease.

KEY WORDS: Cardiovascular disease, Medical history, Body mass index

- HOW TO CITE THIS PAPER : Joshi, Janki and Trivedi, Nidhi (2019). Cardiovascular disease and its association with body mass index: A study of rural women of Uttarakhand. Asian J. Home Sci., 14 (2) : 354356, DOI: 10.15740/HAS/AJHS/14.2/354-356. Copyright@ 2019: Hind Agri-Horticultural Society. 